\title{
Sex Work in SECOND LIFE: SCRIPTS, PRESENCE, AND BOUNDED AUTHENTICITY IN A VIRTUAL ENVIRONMENT
}

\section{MichaEL J. LYNCH \\ Temple University}

The Internet has provided users with an alternative platform for human connection. In the virtual social environment of Second Life, individuals can establish intimate relationships and engage in sexual interactions with others that they may never meet face to face. Such encounters often occur anonymously, removed from the limitations of physical reality and various cultural conventions. Second Life provides a space for individuals to participate in nonnormative behaviors in a virtual setting that do not result in realworld consequences. Although human interest in finding spaces to engage in deviant sex is nothing new, Second Life offers a unique vantage point for the continued examination of such pursuits. In this way, I examine Second Life not only as an intersection of virtual anonymity and non-normative behavior, but also as a novel environment in which to explore how technological transformations in economic and cultural life influence individual erotic experience and the meaning ascribed to sexual expression.

In the following paper, I investigate the dynamics among residents of Second Life who engage in virtual sex for recreation and also as a monetary transaction. Using participant observation and resident interviews, I examine the constructed meanings of their encounters in terms of online intimacy, romance, and cybersex. Informed by Gagnon and Simon's sexual script theory and

Michael J. Lynch is a PhD student in the Department of Sociology at Temple University in Philadelphia PA. He received a B.A. degree in Sociology from West Chester University of Pennsylvania, and an M.A. degree in Science and Technology Studies from Drexel University, Philadelphia, PA. His research interests in sociology focus on the intersection of technology, identity, and economics, as well as the distribution of contemporary domestic labor. Contact can be directed to him at michaellynch575@hotmail.com. 
Bernstein's notion of bounded authenticity, the central question of this project asks: How do individuals experience intimacy and authenticity in a virtual sexual encounter? In other words, how do residents of Second Life construct meaning regarding their sexual encounters in the absence of physical proximity?

Residents were asked to discuss their experiences with online sex and virtual intimacy during their time in Second Life. Based upon the findings of this study, I argue that residents' participation in role play during virtual sex is the critical element to successful erotic encounters and to the maintenance of anonymous, yet authentic, interactions. Representations of gender, aesthetic beauty, and sexual activity in Second Life are primarily based upon Western notions of sexuality. Findings also demonstrate how the use of one's real ${ }^{1}$ voice during virtual sex serves to signal a heightened sense of intimacy and is a premium feature of virtual sex as an erotic service. These findings provide further evidence for Bernstein's notion of bounded authenticity, as virtual sex is a sought-after sexual commodity in Second Life.

\section{Background}

Second Life is a virtual world created by Linden Lab (a privately held American Internet company based in San Francisco) that was launched on June 23, 2003, and is accessible entirely through the Internet. Its users, often referred to as residents, communicate and interact through avatars. Residents can engage in social networking, participate in individual or group activities, as well as create, trade, and own virtual property and services with one another. Every aspect of an avatar is fully modifiable and residents can alter their avatars to take on any form the user chooses (animal, vegetable, or mineral). Similar to a massive multiplayer online role-playing game (MMORPG), Second Life can be played by hundreds of thousands of people at once. Although many residents participate in Second Life strictly for social or business networking, it is also considered

\footnotetext{
${ }^{1}$ The use of "real sex," "real world," "real voice," et cetera, do not serve to deflate the idea that virtual intimacy is any less real, but simply demarcate Second Life activities from non-Second Life activities.
} 
a virtual adult playground for those who wish to fulfill their sexual fantasies by experimenting with homosexuality, owning a brothel of sex slaves, participating in orgies, or paying for cyber-sex. Thus, digitally-mediated intimacy has become a fluid commodity in the virtual marketplace of Second Life and is the centerpiece of inquiry for this paper.

\section{Virtual Identities and Mediated Intimacy}

Identity plays a key role in virtual communities (Smith \& Kollock, 1999). Prior scholarship regarding identity in virtual spaces has focused on the multiplicity of identity construction (Turkle 1995; Flew 2002), gender transcendence (Herring 1996; Warhol 1999; Carlson 2001), and online intimacy (Suler 2004; Turkle 2007). Turkle's notion of multiplicity might be viewed as a challenge to Herring's assertion that cyberspace is actively hostile toward women, as Turkle argues that one can not only assume an online identity that is different from its real world incarnation, but that such identities are potentially infinite. Turkle's conception of cyberspace appears to discount how real world, culturally scripted notions of sexuality and gender performance may be reconstituted in cyberspace. Warhol's (1999) research on online gender performance provides evidence that counters Turkle's notion of multiplicity, as findings demonstrate that online identities are often informed by pre-existing, self-replicating cultural scripts. Further, Valkyrie's (2010) ethnographic study of cybersex interactions in MMORPGs supports this notion as it found that online sex has yet to embrace a broader spectrum of sexuality, even in strictly virtual interactions. Similarly, Kendall's $(2000 ; 2002)$ examinations of how men and women negotiate their gender roles in an online forum the author calls BlueSky, Kendall discovers that the players adhere surprisingly closely to the facts of their actual lives and personalities, despite the common assumption that the online personas men and women create for themselves bear minimal resemblance to reality.

Although virtual identity is of primary significance to those who seek sexual or romantic relations in cyberspace (Turkle 2007), technologically-mediated sex is not indigenous to the online world. Flowers' (1998) examination of the phone sex industry revealed that 
the operators would create a virtual reality in which callers could act out fantasies, but that even those women operators who were skilled at keeping their "true selves" and their phone sex persona separate found that they had to struggle to protect that self and maintain the ability to experience real intimacy. Walther's (1994) research involving groups who work together on identical tasks in cyberspace and in physical proximity, indicated that relationships became even more intimate and sociable than those of face-toface collaborations. Part of this "hyper-personal" effect, Walther hypothesized, comes from people's tendency to present themselves in their best light when using only written words, and part of it, he believed, is due to a mutual idealization in the absence of visual and auditory cues. Thus, participants in virtual interactions often experience a heightened sense of intimacy and a reduced sense of social responsibility toward others as compared to "real-world" interactions (Morahan-Martin and Schumacher 2000; Turkle 2007).

Illouz argued that there is a link between emotions, culture, and economy if we accept the idea that emotions are situated at "the threshold where the non-cultural is encoded in culture, where body, cognition, and culture converge and merge" (1997:3). Illouz framed intimacy as a cultural practice, one that is simultaneously informed by the cultural practice of capitalism. Similarly, Zelizer's (2005) research on intimacy examined its coexistence with monetary transactions and discussed how economic activities have long been embedded in creating and sustaining intimate connections with others. According to Zelizer, authenticity often remains the aim of intimate relationships, with the monetary component of the relationship being ignored, such as with childcare or adoption services. With regard to sexual commerce, Bernstein (2007) argued that spatial and technological changes have influenced the social organization of the commerce of sex and intimacy. Through several years of ethnographic research involving the global prostitution industry, Bernstein found that the discourse of sex-service is not so different from the world of caring services, which both add in human emotion to the task that is being bought and sold. Therefore, the role of a sex worker is not just sex as work, but $\mathrm{s} /$ he may also be a listener, a therapist, or an intimate fantasy creator. Bernstein 
indicated that as opposed to being in monogamous marital state or enduring duo relationship, "the recreational sexual ethic derives its primary meaning from the depth of physical sensation and from emotionally bounded erotic exchange" (2007:6).

Global restructuring of capitalist production has resulted in a sex industry that is now poised to provide consumers the highly sought-after commodity of an authentic (albeit fleeting) intimate sexual encounter. Not only are such encounters desired in the real world, but also in cyberspace where intimacy between two people can be achieved over great distances through technological mediation. This paper intends to bridge the gap between the literature on the commercialization and economy of intimacy in the real world, and the commerce of virtual sex that occurs in Second Life. In the absence of physical proximity, how do residents of Second Life determine notions of intimacy and authenticity in a bounded, virtual encounter? What are the signifiers that determine the varying gradations of authenticity and intimacy therein? A closer examination of these questions follows.

\section{Intersecting Cultural and Virtual Contexts}

\section{Sexual Script Theory}

Working from the perspective of sexual script theory, sexual encounters of all types can be understood as "scripted"- the result of a complex, psychosocial process of development (Gagnon and Simon 1973; Weiderman 2005; Firth and Kitzinger 2007). Thus, sexuality can be understood as a social construct that is learned and proportioned into particular moments in one's lifespan as well as through varying modes of behavior. Conceptually, sexual scripts that operate at the cultural level inform society of the norms and values attached to notions such as "intimacy," "romance," and "sex," as well as how such ideas become socially defined and are performed. In this way, sexual script theory reveals that there is nothing "primal" or "natural" in any real sense with regard to a given sexual encounter-it is simply another social exchange between two or more persons based upon notions of acceptable timing, communication, and sequencing. Jones and Hostler (2002) 
argue that sexual norms and gender roles contribute to the variation in scripts between men and women. Where women are typically expected to be passive and compliant with the initiation of sexual activity, men are often expected to take control of the encounter and to be knowledgeable about sex in general. These expectations are aligned with the Western consensus toward sexuality in which there is a tendency toward serial monogamy as a "normal," heterosexual lifestyle. Sexual script theory is used as a framework for this study in order to identify if/how notions of "intimacy," "romance," and "beauty" are transposed or redefined between the real world and the virtual.

\section{Bounded Authenticity}

Whereas sexual script theory examines the sexual encounter as an exchange between participants that is based upon culturally defined assumptions, Bernstein's theoretical notion of bounded authenticity (2007) examines the sexual encounter as a financial transaction. Bounded authenticity is best understood as the involvement of monetary fees that make up the crucial element of negotiation of boundaries between prostitutes and their clients. According to Bernstein, the new highly sought-after sexual commodity is characterized by an authentic, yet bounded, form of interpersonal connection called the girlfriend experience. This is a transaction in which both the client and the prostitute work hard to stimulate one another and create a sense of what is culturally scripted as "intimacy." In this way, as mentioned above, the role of a sex worker is not just sex as work, but s/he may also be a listener, therapist, or an intimate fantasy creator.

Bernstein's (2007) conceptions of bounded authenticity and the girlfriend experience also lend themselves to the sex industry of the virtual world, where virtual escorts, strippers, and those who sell virtual role-playing services also engage in sexual commerce that is often characterized by varying degrees of anonymity. In this way, intimacy becomes a fluid interconnection that is no longer founded upon the conventional face-to-face, local interaction. As Bernstein points out, the technological advancements of the information age allow for a sense of "global intimacy" wherein boundaries have 
expanded beyond what has typically and publicly been understood as acceptable in "real life." Thus, we might understand the Internet as a mediating technology that facilitates and perpetuates increasing numbers of opportunities for intimate social and sexual relationships that extend significantly further than traditional conceptions of the local. In this way, the lens of bounded authenticity applied in a virtual environment is useful in two ways. First, bounded authenticity allows me to identify if/how culturally scripted notions of authenticity translate into the virtual world. Secondly, it allows me to distinguish how the presence of a monetary transaction plays into the dynamic of an online sexual encounter.

\section{Presence}

The sense of anonymity offered by a virtual social environment such as Second Life presents somewhat of a challenge to Goffman's (1959) front stage/back stage dichotomy. In what might be considered a virtual third stage, private and intimate behavior associated with the back stage is often acted out in a public (albeit virtual) front stage; however, throughout the entire process, one's real-life identity remains uncompromised despite the perceived illusion of non-mediation (Lombard and Ditton 1997). This notion of a perceived illusion refers to the phenomenon of presence, in which an individual perceives a mediated experience as an authentic first-hand experience to which s/he may respond physiologically, cognitively, and emotionally as one would in a non-mediated setting (Lombard and Ditton 1997). A variety of dimensions of presence have been proposed, including Zhao's (2005) discussion of virtual telecopresence. Virtual telecopresence is based on the idea that a person on one end of a line of communication uses an electronic device, such as a networked computer, to get in touch with the person on the other end of the line, which is also connected with a networked device. Through this electronic mediation, two or more people may be able to engage in immediate contact over a great distance. Such examples include speaking with another person via telephone, holding a web-based business conference, or in the case of Second Life, sexual interaction between two avatars.

Presence technologies demonstrate that human beings are 
able to experience real physiological, cognitive, and emotional responses as a result of virtually mediated interactions, often in cases in which two individuals have never met in real life. Therefore, a presence technology such as Second Life not only transcends conceptions of space/time, but also demonstrates the capacity to blur the proverbial line between fantasy and reality. In this way, presence - as a component to my theoretical framework - allows me to examine the sex industry of the virtual world in a way similar to the sex industry of the real world, in which transactions between escorts and their clients are based upon gradations of intimacy and authenticity.

My theoretical frame for this study can be considered a fusion of sexual script theory, bounded authenticity, and presence theory. Sexual script theory will allow me to identify the ways in which cultural meanings surrounding sex may be imported from the real world into a virtual space. Bounded authenticity will be used to observe how such scripted meanings behind sex then translate to a particular market value in the virtual sex industry of Second Life. Presence theory allows me to examine these encounters not as isolated "videogame sex," but as interactions that carry real meanings, emotions, and physiological responses.

\section{Methods}

The method of inquiry chosen for this study was a combination of participant observation and interviews of Second Life residents. This methodological combination was chosen because both interviews and participant observations are particularly suited to capture identifiable narrative and behavioral patterns that inform discourses surrounding virtual sex. Thus, my interest in pinpointing scripted notions of sexuality in a virtual space required me to speak directly with those engaging in online sex in order to search for any potential themes embedded in their personal accounts of such experiences. Yet before being able to enter the virtual field, it was necessary for me to create a Second Life account, download the corresponding software in order to navigate through the Second Life landscape on my home computer, and to create an avatar of 
myself. Thus, on August 26th 2009, I officially entered the field and began to navigate through Second Life with my avatar, "M1chael Loudwater."

Linden Labs requires that any user seeking to access adult content must have their age verified by providing one of several pieces of personal information (e.g., last four digits of social security number or driver's license number). Therefore, it was presupposed that all participants in this study were 18 years of age or older.

Because I was interested in locating and interviewing avatars that would be willing to discuss their sexual activities in Second Life, it became clear that the Second Life red-light district was a fitting starting point for my inquiries. It is not difficult to identify Second Life escorts as they are frequently scantily clad and often are the first to engage in conversation with passers-by. During the participant observation stage of my research, I also found that many exotic dancers in Second Life also work as escorts, which made virtual strip clubs another locale to establish potential interview contacts.

A total of sixteen residents were interviewed (twelve female, four male) during the course of my field work. During the consent process/explanation of research that took place before each interview, I revealed my real-world identity to all respondents in order to establish that the interview was legitimate, and not a gimmick, con-game, or some type of role-play for them to decipher. The cost for a 45-minute interview with a virtual escort ranged from $\$ 800 \mathrm{~L}$ to $\$ 1500 \mathrm{~L}^{2}$, which is an accurate reflection of the price range for erotic services within the virtual escorting industry. Not all of the respondents for this project were escorts, however. Several respondents did indicate that they not only engage in cyber-sex as a monetary transaction, but also engage in it for personal pleasure and entertainment before and after becoming an escort. Thus, the respondents have participated in virtual sex as paid providers, as well as consumers.

The interviews often took place in sitting areas of strip clubs or outside on themed patio vistas. Some of the escorts I interviewed welcomed me back to their virtual "flat" or apartment where they

2 "L" for Lindens: the Second Life currency where $\$ 1000 \mathrm{~L}$ roughly converts to \$4 U.S. dollars. 
would typically bring a client. After I was able to establish a relative sense of credibility, the interviews began.

Many questions in my interview schedule focused on simple biographical data, ranging from how long the participant had been a resident of Second Life to what the participant generally used Second Life for (e.g. social networking, business, romance, or cyber-sex). In order to determine scripted notions of desirable and undesirable virtual sex, I asked participants their opinions on what they would consider "an evening of good sex" as well as what constituted "bad sex" in Second Life. I also asked participants their preferences relative to text-based or real voice chat, their explanations for such preferences, and/or why a participant may or may not offer real voice escorting services. The questions pertaining to textbased or real voice communication were successful in identifying meanings associated with the use of real voice and gradations of online intimacy. Because I utilized a snowball sampling procedure, I ended all interviews with an inquiry into whether the participant knew of any other residents who may be interested in speaking with me regarding the matters we discussed.

Interview transcripts and field notes from the participant observation phase of the study were first coded and analyzed to distinguish overall themes, and then a more in-depth, interpretive code was used to identify specific trends and patterns.

\section{Findings}

Based on participant observation and resident interviews, several themes were identified regarding sexual experiences in the virtual world.

\section{Western Cultural Scripts}

First, virtual sex in Second Life indeed does appear to import real-world cultural scripts for sexuality, behavior, and desirability. Although residents are able to participate in the space/time transcending act of continual redefinition of their avatar's identity, gender, and sexual prowess, notions of human sexuality in Second Life are predominantly based upon typical Western conceptions. 
The appearance of users' avatars primarily draw upon real-world scripted notions of aesthetic beauty and eroticism. Thus, male avatars' faces reflect the archetypical "chiseled" features (often with permanent/perfect "five o'clock shadow"), and are all seemingly tall and handsome with sculpted abdominal muscles. These images are typical of what one might expect to find in fashion magazines or men's underwear advertisements. Similarly, female avatars often appear to have thin waists, large breasts, and perfectly styled hair. Additionally, the software within Second Life that allow for avatars to engage in the visual act of sex is also based on Western scripts for sexual positions and scenarios. For example, animation software, or "poseballs" for pole dancing, is based upon a combination of various stereotypical erotic dance movements such as gyration, slowmotion, and other sexually suggestive body language. The option to upgrade a male avatar's virtual penis is reflective of Western culture's obsession with male "endowedness." Thus, similar to Kendall and Valkyrie's findings mentioned earlier, sexuality in Second Life does not necessarily signal the transcendence of deeply entrenched cultural assumptions, discourses, and categories of Western society, but are instead reproduced in a virtual space.

\section{Significance of Role Play}

In the absence of physical proximity, residents of Second Life rely on role-play to create a shared sense of intimacy that is unique to a given sexual encounter.

Role-playing in Second Life can best be understood as a form of story creation between two or more residents. During virtual sex, a resident's ability to articulate the interaction in real time is integral to creating a shared sense of intimacy and is central to having "good sex" in a virtual space. The quality of a virtual sexual encounter in Second Life typically depends upon the players' abilities to evoke a vivid, visceral mental picture in the minds of their partners in the form of role-play. Similarly, the inability to discuss the encounter articulately or creatively is often associated with "bad sex," and signifies one's inexperience with role-play. Participants reported that the mutual creation of storylines or erotic fantasy during virtual sex serves to make a particular encounter unique to the individuals 
involved. Role play situations can range from more conventional sexual scripts to scenarios in which participants act as vampires or werewolves.

When we envision what has been culturally scripted as what constitutes "good sex" in the contemporary Western world, responses regarding the optimal physical and physiological aspects of the human bodies involved might be commonly expected (i.e., physical attraction, being able to have sex for an extended length of time, the avoidance of prematurely reaching climax). Yet respondents' conceptions of "good sex" in Second Life are seemingly unbound to the physical laws of gravity and endurance that often govern notions of desirable sexual interactions of the real world. Considering that software animations allow for two avatars to theoretically have continual animated sex for an indefinite amount of time, "good sex" in the virtual world is not so much predicated on duration, but rather on articulation. One's avatar being able to engage in sexual activity (although an important component to cyber sex) is not enough. One must also be capable of creatively articulating the interaction in real time either through text-chat or real voice during the encounter. "Angelica Huntress" 3 discussed how integral role-play is to her sexual encounters:

Angelica Huntress: I have great role players and damn, can they get me ummm well...

Angelica Huntress: it is like reading a romance novel that you create

M1CHAEL Loudwater: Care to elaborate on your great role players?

Angelica Huntress: for example if I may give you one ?

\section{M1CHAEL Loudwater: Sure}

\footnotetext{
${ }^{3}$ All avatar names have been changed to protect participants' Second Life identities. At no point during the interview process were respondents' real life names documented.
} 
Angelica Huntress: “... reaches up her hands caressing his bare chest as she leans forward placing a soft kiss to his sculpted pec. Her long soft tresses gently brushing his heated flesh. Slowly she works her kisses down as she finds herself before his long hard member, tucking her bottom lip between her teeth she whispers softly 'may I?' her breath hot against his skin...

,

Angelica Huntress: and then [male partner] would reply

Angelica Huntress: it is like writing a story

M1CHAEL Loudwater: I see.

Angelica Huntress: to me it is what makes good virtual and cyber sex

Angelica Huntress: "do you want to fuck?" is not sensual at all

Angelica Huntress: two [avatars] exchanging thoughts and role play is hot and sexy and the way to my cyber loins.

Similarly, "Missy Swordthain" commented on the importance of role play as well as the "do's and don'ts" of Second Life cruising etiquette in general:

Another thing is profile readers. When one reads a profile [prior to a sexual encounter] they know in some aspects of who you are and get to know you better. Someone coming from out of the blue hitting on you and not in the polite way, 'hey, nice tits, can I touch them and squeeze them?' calls for an either instant mute or ban. Good sex involves a passionate role play though. You have to know how to role play. I've been role playing for years so it kind of comes natural to me and boggles some people when I walk around talking and role playing like I do. Good role players can make a sexual scene go on for hours and hours if they want to. 
In contrast to the idea of what equates to desirable sex, a follow-up question asked respondents "What constitutes 'bad sex' in Second Life?" Male escort "Henry Grant" commented on the absence of the ability to engage in good role playing as seemingly indicative of "bad sex":

M1CHAEL Loudwater: Well what constitutes "bad sex" in Second Life?

Henry Grant: lol. newbies that just lay there no talk or nothing

Henry Grant: Second Life is a HUGE role-play game

Henry Grant: it allows people to do things they would never do in real [life]

These respondents' remarks reveal how speaking the act is most integral to the potential for erotic "success." The idea that the written or spoken representation of a sexual interaction can produce the same physiological effect that the physical act produces highlights how speaking the interaction is perhaps not too unlike the doing of it. As the human orgasm originates in the brain, the physical act of sex is but one mechanism in reaching orgasm, as the physiological response-inducing capabilities of presence technologies demonstrate.

\section{The Virtual Partition: Text Chat versus Real Voice}

The use of real voice serves to construct a heightened level of authenticity during virtual sex. Real voice-based cyber sex is a highly sought-after commodity in Second Life, and virtual escorts are able to command a higher price for such services compared to text-based encounters. Participants reported that being able to hear their partner's breathing during virtual sex made the encounter feel more like real sex. Other escorts, however, reported that real voice is too intimate and symbolizes a boundary in their services that they are not willing to cross.

Respondents commented on the text-chat/real-voice dichotomy 
in regard to the communicative aspects of a virtual sexual encounter. Responses highlight how the use of one's real voice versus one's keyboard to communicate inside Second Life carries multiple meanings for escorts and their clients because the use of one's real voice enhances the perception of presence and subsequently enhances the perception of intimacy. For some respondents, textchat and real voice serve as indicators of either the presence or absence of a virtual "partition;" a demarcation between the real world and the fantasy world.

M1CHAEL Loudwater: Do you always type chat when working or do you ever speak in your real voice?

Katharina Olivier: I tried voice but it was a step too intimate for me. Too [real life]...I stopped it after 3 months. And I would also never do cam-sex.

Similarly, "Angelica" commented on the use of real voice as well as its implication in her real life marriage:

M1CHAEL Loudwater: Do you ever use your real voice in your role playing scenarios?

Angelica Huntress: [real voice] is against my role play boundaries that my husband and I have agreed to... it will bring it into real... voice is personal. No voice, no real photos...minor real info given out [to clients].

The respondents' answers speak to the idea that the virtual partition provided by text-based chat is needed to uphold a sense of anonymity and that one's real voice brings the sexual encounter too much into the realm of the real world, a line that neither of the respondents are willing to cross. Other escorts, however, have capitalized on the use of their real voices as it is well understood that real voice cyber-sex is considered an upgrade or a premium feature in the sexual encounter, thus allowing an escort to charge a client more money. "Jaime Buttons" comments on her voice 
escorting business:

Jaime Buttons: “...the making money part sounded great! and I met some good people who helped me change my look, doll me up, and I became a voice escort... worked a few clubs then my business student side in me came through, and I realized I really wanted to try my hand at owning a business, so I started my own club and that's what I've done thus far (escorting) Sex sells...so here we are."

This respondent (who also reported being married in the real world) also discussed how she is able to strike a clear balance between her Second Life escorting identity and her real-world self. She cites her escorting as strictly a business transaction; a total suspension of real emotions.

Jaime Buttons: "[my real life husband] has listened a couple times in and out...and knows that its a business transaction for me...I don't call these men, give my number, or personal email...and I don't become anything more serious than a friend to them. He's not a jealous type...we trust each other and he knows I'd never take it beyond [Second Life]...It's not physical contact with each other...so I don't consider it cheating...because I don't have [real life] feelings for that client...it's business."

Escort "Carly Sunshine" offers similar commentary regarding the suspension of real emotions during real-voice cyber sex.

Carly Sunshine: "[real voice cyber sex] does nothing for me sexually...sometimes when I really think about it I feel a little silly but as long as they're willing to pay for it I'll keep doing it!"

These respondents' comments regarding their voice escorting businesses reflects Bernstein's discussion of bounded authenticitythe idea that the sexual encounter is temporarily bounded in the form of a monetary transaction without the typical long term, monogamous commitments associated with having a steady sex life. The escort's real voice serves to authenticate a heightened level of intimacy, but only for the length of time of the encounter, as the intimate exchange is ultimately a fleeting business transaction. Respondent "Honey Bunny" comments on this dynamic: 
M1CHAEL Loudwater: Do you think about the clients you have had when you are in real life?

Honey Bunny: "No. I don't think about them at all actually. Once our time is up, that's it. I mean it's exciting sometimes in the moment of it but it's not like I'm sitting around dreaming about them after.

Honey Bunny: It's really about getting paid for me. I'm a business major."

This respondent's comments highlight how virtual escorting in Second Life as service work is aptly captured by the concept of bounded authenticity, where seemingly any and every type of intimate exchange between two people can be bought and sold at the right price.

Contrary to Walther's argument mentioned earlier that the lack of auditory signals creates greater intimacy between two online collaborative partners, these escorts' comments on sex work in Second Life appear to offer a counter finding. Walther's argument, however, must be considered in the context of workplace relations and online collaborative work dynamics, whereas virtual sex in Second Life is different in the sense that real voice serves as a way to enhance intimacy; it is another component in a sexual script or role play scenario in which the sound of another person's voice or breathing heightens the level of eroticism. Also, as Walther's research was published in 1994 the ubiquity of real voice in $21^{\text {st }}$ century online interaction (which is arguably integral to the maintenance of presence in Second Life) was not yet realized. Thus, the Internet as a cultural institution in 2009 is fundamentally different from the Internet of 1994.

\section{Conclusion}

As fledgling technologies of the past have often been first exploited for sexual purposes ${ }^{4}$, an argument could be made that

${ }^{4}$ Such as how the first moving pictures or "stag" films depicted naked women, 
sex in Second Life is nothing more than what respondent "Tina Lavender" referred to as simply "a new and different aid to masturbation." Perhaps we might frame sex work in Second Life as "old wine in a new bottle"; one of the oldest human interactions performed in a novel, technologically mediated environment. Yet considering that virtual sex allows individuals to circumvent unwanted labels and meanings associated with real-world behavior, residents in Second Life are able to experiment and experience erotic encounters that they might otherwise choose not to engage in were the encounter to occur in the real world.

In the absence of physical proximity, Second Life residents' participation in role play serves to compensate for the absence of physical intimacy during virtual sex and often signals the degree of "success" of such encounters. Based upon the responses of virtual escorts and consumers of cyber-sex interviewed for this study, a resident's ability to articulate the interaction in real time is integral to the maintenance of presence and to achieve "good sex." Text-based chat or the use of a person's real voice determine the gradations of authenticity and sexual intimacy, where real voice often implies a heightened sense of intimacy and serves to determine the absence of a "virtual partition" between participants. The shared meanings behind text-based and real voice communication translate into gradations of price in the virtual sex industry, as consumers of virtual escorting services are willing to pay more to hear the voices of their erotic service providers.

A virtual environment such as Second Life allows for those who would not typically engage in certain activities within real life to participate in what may be considered transgressive behavior under a perceived sense of anonymity, and to "try on" different genders. Thus, these findings are indicative of the ubiquitous intersecting of computers, the construction of virtual sexual identities, and erotic experience. Such an intersection provides support for the characterization of the Western cultural system as immediate experience- and consumption-oriented (see Bauman

the emergence of the VCR on the consumer market was largely spurred by the pornographic film industry, the majority of Internet content during its first few years was primarily pornography. 
1997). As sociologists, recognizing virtual sex as a commodity is perhaps useful in identifying the larger, socially constructed continuum of sexual identity and experience, where not all forms of expression and interaction are grounded in physical reality. Although Second Life allows people to engage in sex as a virtual animal, vegetable, or mineral in potentially infinite shifting social contexts, my observations in this novel environment revealed the pervasiveness of Western scripted notions of sexuality and aesthetic desirability. Thus, sex in Second Life does not necessarily signal the transcendence of deeply entrenched cultural assumptions, discourses, and categories of Western society, but are instead reproduced in a virtual environment. While the world continues on its trajectory of globalization, online intimate relations and sex work require a closer examination, and the virtual world of Second Life provides fertile ground for such inquiries.

\section{Bibliography}

Bauman, Zygmunt. 1997. Postmodernity and its Discontents. New York: New York University Press.

Bernstein, Elizabeth. 2007. Temporarily Yours: Intimacy, Authenticity, and the Commerce of Sex. Chicago, IL: University of Chicago Press.

Carlson, D. 2001. "Gay, Queer, and Cyborg: The Performance of Identity in a Transglobal Age." Discourse: Studies in the Cultural Politics of Education 22:111-121.

Firth, Hannah and C. Kitzinger. 2007. "Reformulating Sexual Script Theory." Theory and Psychology 11(2):209-232.

Flew, T. 2002. New Media: An Introduction. Victoria: University of Victoria Press.

Flowers, A. 1998. The Fantasy Factor: An Insider's View of the Phone Sex Industry. Philadelphia, PA: University of Pennsylvania Press.

Gagnon, J.H. and W. Simon. 1973. Sexual Conduct: The Social Sources of Human Sexuality. Chicago: Aldine.

Goffman, E. 1959. The Presentation of Self in Everyday Life. Garden City, NY: Doubleday.

Herring, Susan. 1996. "Posting in a Different Voice." Pp. 56-84 in Philosophical Perspectives on Computer-Mediated-Communication, edited by C. Ess. New York: State University of New York Press.

Illouz, Eva. 1997. Consuming the Romantic Utopia: Love and the Cultural Contradictions of Capitalism. University of California Press. 
Jones, L. Stanton and H.R. Hostler. 2002. "Sexual Script Theory: An Integrative Exploration of the Possibilities and Limits of Sexual Self-Definition." Journal of Psychology and Theology 30:120-131.

Kendall, Lori. 2000. "Oh No! I'm a Nerd!: Hegemonic Masculinity On an Online Forum." Gender and Society 14(2):256-274.

Kendall, Lori. 2002. Hanging Out in the Virtual Pub: Masculinities and Relationships Online. Berkeley, CA: University of California Press.

Lombard, M. and Ditton, T. 1997. "At The Heart of it All: The Concept of Presence." Journal of Computer-Mediated Communication, 3(2). Retrieved November 15, 2009 (http://www.ascusc.org.jcmc/vol3/ issue2/lombard.html).

Morahan-Martin, J. and Schumacher, P. 2000. "Incidence and Correlates of Pathological Internet Use Among College Students." Computers in Human Behavior 16:13-29.

Smith, M. and P. Kollock. 1999. Communities in Cyberspace. Routledge. Suler, J.R. 2004. “The Psychology of Text Relationships.” Pp. 118-129 in Online Counseling: A Manual for Mental Health Professionals, edited by R. Kraus, J. Zack, and G. Striker. London: Elsevier Academic Press.

Turkle, S. 1995. Life on the Screen: Identity in the Age of the Internet. New York: Simon and Schuster. Turkle, S. 2007. "Authenticity in the Age of Digital Companions." Interaction Studies, 8:501-517.

Valkyrie, Zek Cypress 2010. "Cybersexuality in MMORPGs: Virtual Sexual Revolution Untapped." Men and Masculinities. May 2010, pp. 2-21.

Walther, J. B. 1994. "Interpersonal Effects in Computer-Mediated Interaction:AMeta-Analysis of Social and Antisocial Communication." Communication Research, 21:460-487.

Warhol, Robyn R. 1999. "The Inevitable Virtuality of Gender: Performing Femininity on an Electronic Bulletin Board for Soap Opera Fans." Pp. 91-107 in Virtual Gender: Fantasies of Subjectivity and Embodiment, edited by M. O'Farrell and L. Valone. University of Michigan Press.

Zelizer, Viviana. 2005. The Purchase of Intimacy. Princeton University Press.

Zhao, S. 2005. "Toward a Taxonomy of Copresence." Presence: Teleoperators and Virtual Environments 12:445-455. 